\title{
DIRECT GEOREFERENCING : A NEW STANDARD IN PHOTOGRAMMETRY FOR HIGH ACCURACY MAPPING
}

\author{
Aldino Rizaldy, Wildan Firdaus \\ National Coordination Agency for Survey and Mapping (BAKOSURTANAL), Cibinong, Indonesia - \\ aldino.rizaldy@bakosurtanal.go.id \\ Comission I, WG I/1 \\ XXII ISPRS Congress, Melbourne $25^{\text {th }}$ August $-1^{\text {st }}$ September 2012
}

KEY WORDS: Direct Georeferencing, Digital Photogrammetry, GPS/IMU, Exterior Orientation

\begin{abstract}
:
Direct georeferencing is a new method in photogrammetry, especially in the digital camera era. Theoretically, this method does not require ground control points (GCP) and the Aerial Triangulation (AT), to process aerial photography into ground coordinates. Compared with the old method, this method has three main advantages: faster data processing, simple workflow and less expensive project, at the same accuracy. Direct georeferencing using two devices, GPS and IMU. GPS recording the camera coordinates (X, Y, $\mathrm{Z}$ ), and IMU recording the camera orientation (omega, phi, kappa). Both parameters merged into Exterior Orientation (EO) parameter. This parameters required for next steps in the photogrammetric projects, such as stereocompilation, DSM generation, orthorectification and mosaic. Accuracy of this method was tested on topographic map project in Medan, Indonesia. Large-format digital camera Ultracam X from Vexcel is used, while the GPS / IMU is IGI AeroControl. 19 Independent Check Point (ICP) were used to determine the accuracy. Horizontal accuracy is 0.356 meters and vertical accuracy is 0.483 meters. Data with this accuracy can be used for 1:2.500 map scale project.
\end{abstract}

\section{INTRODUCTION}

\subsection{Description and Ability}

GPS/IMU technology has bring the new paradigm in digital photogrammetry. GPS record coordinate $(\mathrm{X}, \mathrm{Y}, \mathrm{Z})$ and IMU record orientation (omega, phi, kappa) of image exposure. These 6 parameters are called Exterior Orientation (EO) parameter, which are needed in photogrammetry. In a traditional photogrammetry, EO parameter are derived from Aerial Triangulation (AT). It also need Ground Control Points (GCP) which are distributed evenly.

The method which EO parameter recorded directly from GPS/IMU called Direct Georeferencing. Based on this ability, theoritically, it does not require GCP and it can replace AT process. In the other word, Direct Georeferencing totally bypass AT with no GCP requirement, except for $\mathrm{Q} / \mathrm{C}$ and $\mathrm{Q} / \mathrm{A}$ (Mostafa, 2011b). It gives a shorter time and cheaper in the mapping project and simple workflow, due to complexity in AT process. It also gives lower cost project.

Another reserach (Mostafa, 2011a) has investigate practical Direct Georeferencing method using POS/AV device from Applanix, compare to theoretical specification. Result proves that this method meet the accuracy from theoritical specification.

Continues Reference Station (CORS) which extensively used now, also has a potential to used in Direct Georeferencing. CORS has an ability to support high accuracy $3 \mathrm{D}$ positioning activity, especially when the station are densified and data frequency is increased to $1-2$ seconds interval instead of the 15 - 30 seconds interval (Mostafa, 2001c).
However, the most challange in this method is when images are to be processed in stereocompilation, which parallax issue are very critical. An investigation about this result that it still need AT followed by bulk orientation to solve parallax problem (Madani, 2001). Performing AT also permits modeling the unaccounted systematic errors using self-calibration techniques. This is also explained by (Scroth, 2004), Direct Georeferencing method can be extensively used for orthophoto generation, but it still need AT for stereocompilation work. To improve the accuracy, it is possible to do by using Integrated Sensor Orientation (Skaloud, 2007).

\subsection{GPS/IMU}

1.2.1 Applanix POS/AV. Launched by brand that are wellknown of their product in Direct Georeferencing system, Applanix POS/AV offer great ability for real time and postprocessed Direct Georeferencing. It system integrating precision GNSS with small format, lightweight and high measurement rates IMU inertial tecnology. It also include postprocessed software and optional photogrammetry tool, such as boresight calibration and quality control. Applanix POS/AV offer severel types of IMU depend on the accuracy. It also provide Track'air Flight Management System.

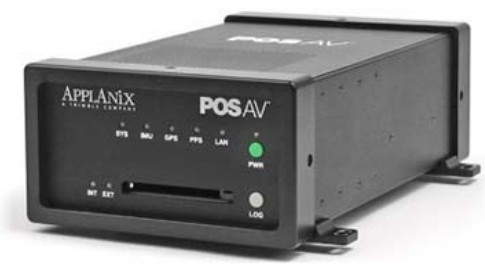

Figure 1. Applanix POS/AV (source: Applanix) 


\begin{tabular}{|c|c|c|c|}
\hline POS AV & $\mathbf{4 1 0}$ & $\mathbf{5 1 0}$ & $\mathbf{6 1 0}$ \\
\hline Position (m) & $0.05-0.30$ & $0.05-0.30$ & $0.05-0.30$ \\
\hline Velocity (m/s) & 0.005 & 0.005 & 0.005 \\
\hline $\begin{array}{c}\text { Roll \& Pitch } \\
\text { (deg) }\end{array}$ & 0.008 & 0.005 & 0.0025 \\
\hline $\begin{array}{c}\text { True Heading } \\
\text { (deg) }\end{array}$ & 0.025 & 0.008 & 0.005 \\
\hline $\begin{array}{c}\text { Noise } \\
\text { (deg/sqrt(hr) })\end{array}$ & $<0.10$ & $<0.02$ & $<0.005$ \\
\hline Drift (deg/hour) & 0.50 & 0.10 & $<0.10$ \\
\hline
\end{tabular}

Table 1. Applanix POS/AV Specification (source: Applanix)

1.2.2 Leica IPAS20. Launched by brand that are wellknown in Geospatial, Leica IPAS20 has a several advantages. It offer several option of different type of IMU. It also has a flexible interfaces which support various sensor type as well as multi sensor system with up to four sensors. Leica IPAS20 has a compatibility with Leica FCMS Flight \& Sensor Control Management System or other $3^{\text {rd }}$ party flight management sytem. It also equipped with post processing software which blends IMU data and GPS trajectory to provide robust, post mission solution.

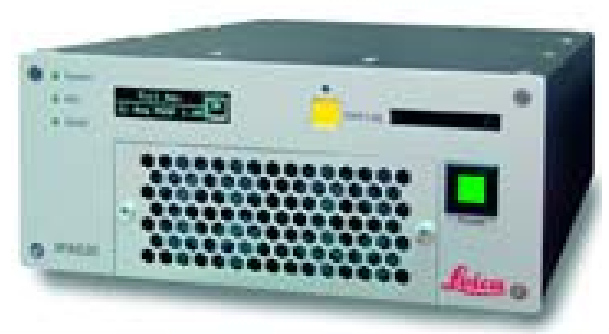

Figure 2. Leica IPAS20 (source: Leica)

\begin{tabular}{|c|c|c|c|c|}
\hline IPAS20 & NUS4 & DUS5 & NUS5 & CUS6 \\
\hline Position (m) & $\begin{array}{c}0.05- \\
0.30\end{array}$ & $\begin{array}{c}0.05- \\
0.30\end{array}$ & $\begin{array}{c}0.05- \\
0.30\end{array}$ & $\begin{array}{c}0.05- \\
0.30\end{array}$ \\
\hline Velocity (m/s) & 0.005 & 0.005 & 0.005 & 0.005 \\
\hline $\begin{array}{c}\text { Roll \& Pitch } \\
\text { (deg) }\end{array}$ & 0.008 & 0.005 & 0.005 & 0.0025 \\
\hline $\begin{array}{c}\text { True Heading } \\
\text { (deg) }\end{array}$ & 0.015 & 0.008 & 0.008 & 0.005 \\
\hline $\begin{array}{c}\text { Noise } \\
\text { (deg/sqrt(hr) })\end{array}$ & $<0.05$ & $<0.01$ & $<0.01$ & $<0.01$ \\
\hline Drift (deg/hour) & $<0.5$ & $<0.1$ & $<0.1$ & $<0.01$ \\
\hline Data Rates & $200 \mathrm{~Hz}$ & $200 \mathrm{~Hz}$ & $500 \mathrm{~Hz}$ & $200 \mathrm{~Hz}$ \\
\hline
\end{tabular}

Table 1. Leica IPAS20 Specification (source: Leica)
1.2.3 IGI AEROcontrol. Launched by IGI that are wellknown with their GNSS/IMU product, IGI AEROcontrol is consist of an IMU-IIe based on Fibre-Optic Gyros (FOG)) and Sensor Management Unit (SMU) with integrated high end GNSS receiver. It has post-processing software, AEROoffice, that provide forward/backward Kalman filter algorithm to achieve optimal results even under challenging condition. It can combined with IGI CCNS4 Mission Planning and Sensor Management System or $3^{\text {rd }}$ party software for perfect solution. IGI AEROcontrol offers several types of IMU specification.
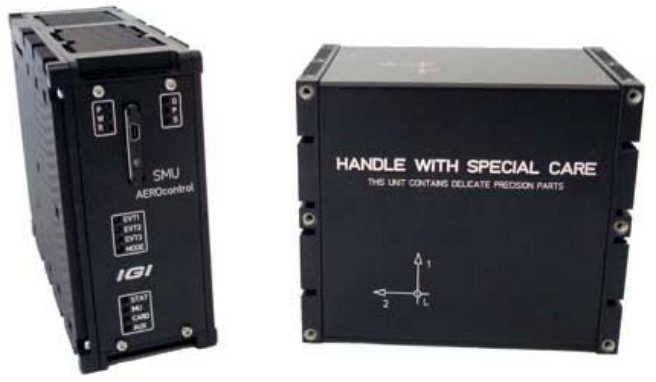

Figure 3. IGI AEROcontrol (source: IGI)

\begin{tabular}{|c|c|c|c|}
\hline AEROcontrol & I & II & III \\
\hline Position (m) & 0.05 & 0.05 & 0.05 \\
\hline Velocity (m/s) & 0.005 & 0.005 & 0.005 \\
\hline $\begin{array}{c}\text { Roll \& Pitch } \\
\text { (deg) }\end{array}$ & 0.008 & 0.004 & 0.003 \\
\hline $\begin{array}{c}\text { True Heading } \\
\text { (deg) }\end{array}$ & 0.015 & 0.01 & 0.007 \\
\hline $\begin{array}{c}\text { Noise } \\
\text { (deg/sqrt(hr)) }\end{array}$ & 0.005 \\
\hline Drift (deg/hour) & \multicolumn{3}{|c|}{0.03} \\
\hline Data Rates & $\begin{array}{c}128 / 256 \\
\mathrm{~Hz}\end{array}$ & $\begin{array}{c}128 / 256 \\
\mathrm{~Hz}\end{array}$ & $400 \mathrm{~Hz}$ \\
\hline
\end{tabular}

Table 3. IGI AEROcontrol Specification (source: IGI)

\section{DATA AND METHODOLOGY}

\subsection{Data}

To determine the accuracy of Direct Georeferencing method, hundred of photos are acquired from digital large format camera Vexcel UltraCam $\mathbf{X}$. The system equipped with IGI AEROcontrol to record EO parameter, IGI CCNS4 Flight \& Sensor Management System, and Somag GSM3000 camera mount which has a gyro-stabilized ability.

Images are acquired from 3,000 m AGL flying height from Pilatus Porter airplane and has approximately $21.5 \mathrm{~m}$ ground resolution. Photo scale is about 1:30.000.

These data actually used for 1:10.000 map scale project, held by BAKOSURTANAL (National Coordination Agency for Survey and Mapping) which has responsibility to provide topographic map in various map scale in Indonesia. 
Beside used for mapping project, the data can also used for research to calculate an accuracy of Direct Georeferencing since its project has many GCP spread distributed evenly (fig. 4) and has GPS/IMU data for each images. The images also processed using traditional AT to detemine EO parameter.

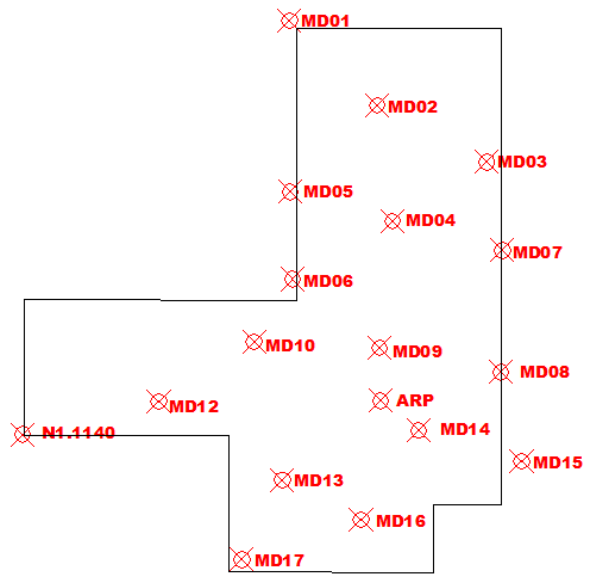

Figure 4. GCP Distribution

The project held on Medan, Indonesia. It is urban area and one of big city in Indonesia. Medan has a relatively flat area.

\subsection{Methodology}

Direct Georeferencing started from camera calibration and boresight caliration to determine camera distortion and boresight misalignment. Boresight calibration held on small area using ideal GCP distribution and ideal flight plan at lower flying height to obtain high accuracy result. The result is boresight misalignment and will be used to correct EO parameter derived from GPS/IMU.

Since Direct Georeferencing does not need GCP, all GCP in this project can be changed into Independent Check Points (ICP) to check the accuracy of this method. RMSE can be calculated by using 3D-glasses to measure coordinates for each GCP (from stereomodels generated by EO parameter from GPS/IMU, not from AT) and then compare these coordinates to original coordinates from static GPS measurement in field survey (assumed as true value).

EO Parameter recorded from raw data GPS/IMU, then postprocessed using IGI AEROoffice to provide most optimal results. These parameter then compared to EO parameter calculated from AT (assumed as true value) to determine the accuracy of GPS/IMU.

\section{RESULT}

\subsection{Independent Check Points (ICP)}

Accuracy of Direct Georeferencing in this mapping project can be calculated from compare it with GCP which changed to ICP since GCP does not used in Direct Georeferencing method. The results show that this method has good RMSE and meet the requirement from BAKOSURTANAL to produce 1:10.000 map scale. The requirements are 2 meter accuracy for planimetric and 2.5 meter accuracy for vertical.

\begin{tabular}{|c|c|c|}
\hline Point & dXY & dZ \\
\hline MD01 & 0.339 & 0.001 \\
\hline MD02 & 0.221 & -0.268 \\
\hline MD03 & 0.412 & -0.281 \\
\hline MD04 & 0.449 & 0.051 \\
\hline MD05 & 0.173 & 0.035 \\
\hline MD06 & 0.575 & -0.062 \\
\hline MD07 & 0.402 & -0.762 \\
\hline MD08 & 0.422 & 0.066 \\
\hline MD09 & 0.364 & -0.119 \\
\hline MD10 & 0.283 & 0.688 \\
\hline MD12 & 0.110 & 1.077 \\
\hline MD13 & 0.181 & -0.255 \\
\hline MD14 & 0.205 & 0.009 \\
\hline MD15 & 0.148 & -0.025 \\
\hline MD16 & 0.378 & 0.36 \\
\hline MD17 & 0.224 & 0.103 \\
\hline ARP & 0.665 & 0.237 \\
\hline N1.1140 & 0.286 & 1.245 \\
\hline RMSE & $\mathbf{0 . 3 8 6}$ & $\mathbf{0 . 4 8 3}$ \\
\hline
\end{tabular}

Table 4. Independent Check Points Result



Figure 6. Graphic of ICP deviation 


\subsection{EO Parameter Gaps}

Accuracy of EO parameter derived by GPS/IMU can be calculated by compare it with EO parameter derived from traditional AT process (assumed as true values). The results show a high accuracy for position (Table. 5) and orientation parameter (Table. 6).

\begin{tabular}{|c|c|c|c|}
\hline & $X(\mathrm{~m})$ & $\mathrm{Y}(\mathrm{m})$ & $\mathrm{Z}(\mathrm{m})$ \\
\hline Min & -0.032 & -0.015 & -0.103 \\
\hline Max & 0.158 & 0.176 & 0.170 \\
\hline RMSE & 0.07898 & 0.09405 & 0.06047 \\
\hline
\end{tabular}

Table 5. Statistics of Position parameter from GPS/IMU

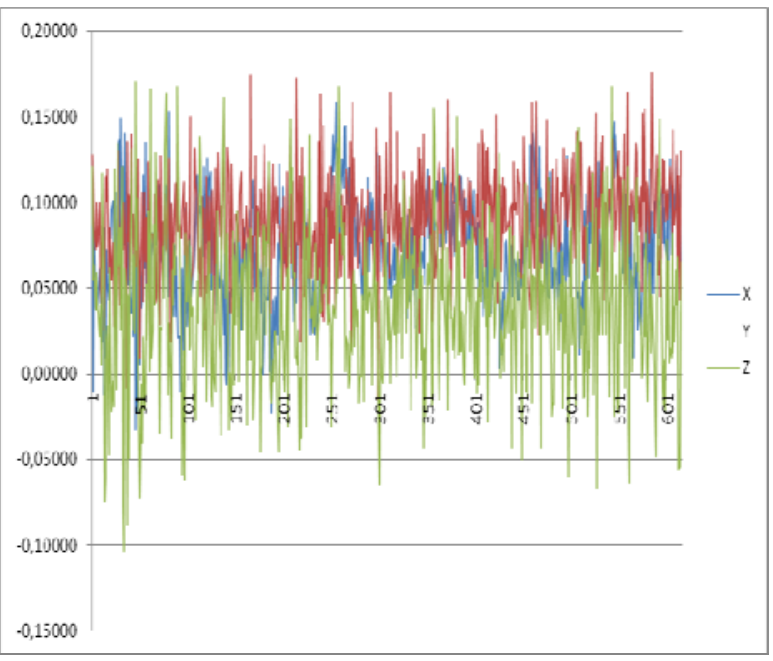

Figure 7. Graphic of Position parameter gaps

\begin{tabular}{|c|c|c|c|}
\hline & Omega (deg) & Phi (deg) & Kappa (deg) \\
\hline Min & -0.01872 & -0.01252 & -0.02795 \\
\hline Max & 0.01608 & 0.01280 & 0.02316 \\
\hline RMSE & 0.00567 & 0.00462 & 0.00706 \\
\hline
\end{tabular}

Table 6. Statistics of Orientation parameter from GPS/IMU

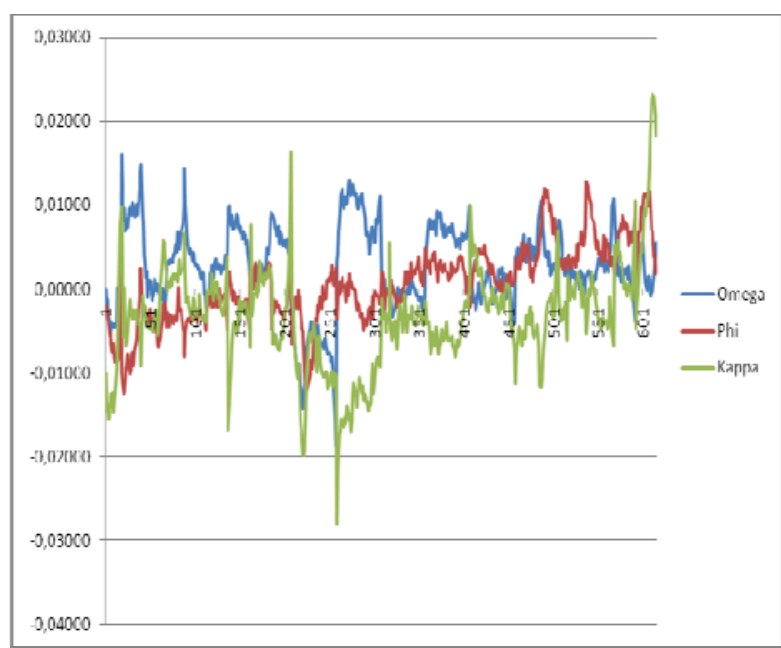

Figure 8. Graphic of Orientation parameter gaps

\section{ANALYSIS}

\subsection{Maximum Map Scale Achieved}

Maximum map scale that will be achieved for this data will determine using calculation from (Amhar, 2000).

$$
\sigma \leq \mathrm{S} / 5000
$$

where $\sigma=$ accuracy of data

$$
\mathrm{S}=\text { map scale }
$$

If the RMSE rounded to 0.5 meter so it will achieved until 1:2.500 map scale.

According to requirement from BAKOSURTANAL, 1:2.500 map scale need 0.5 meter accuracy for planimetric and 0.625 meter accuracy for vertical.

\subsection{Boresight Calibration}

Boresight Calibration is very important step in Direct Georeferencing method. It eliminate error due to different coordinate system between sensor and IMU, called boresight misalignment. This error calculated using AEROoffice from IGI. If this error exist, it makes EO parameter are not accurate enough. The results of Boresight Calibration are shown at Table 7.

\begin{tabular}{|c|c|c|}
\hline Roll (deg) & Pitch (deg) & Yaw (deg) \\
\hline 0.0750 & -0.0448 & -0.0897 \\
\hline
\end{tabular}

Table 7. Boresight Alignment 
In addition to boresight misalignment, there are also a correction for leverarm sensor, which is a different between sensor and GPS antenna. This correction are shown at Table 8.

\begin{tabular}{|c|c|c|}
\hline \multicolumn{3}{|c|}{ Leverarm Sensor } \\
\hline $0.140 \mathrm{~m}$ & $-0.010 \mathrm{~m}$ & $0.506 \mathrm{~m}$ \\
\hline
\end{tabular}

Table 8. Leverarm Sensor

From the table above, it can easily conclude that both correction is a mandatory for Direct Georeferencing method to achieve high accuracy result, due to the value of both correction are significantly larger than RMSE.

\subsection{Y - Parallax}

Main challenge for Direct Georeferencing method is when images will be generate into stereomodels to stereocompilation to produce line map. The most important issue is stereocompilation must free of parallax. It is difficult for operator to identify the elevation of object's surface from stereomodels if parallax still remain. In traditional AT, relative orientation eliminate parallax and the images are ready for stereocompilation.

When stereoplotting operator start to extract some features like road, river and breakline from stereomodels generated by EO parameters from this method, it was little different compared with stereomodels generated from EO parameter from AT. But it is still possible to extract some features because there is only a very little y-parallax exist, almost free y-parallax. Stereomodels from this method as good as stereomodels from AT. But it still must be carefull to do stereocompilation from this method, it must be examined before to detect if there is a yparallax remain.

\section{DISCUSSION}

\subsection{Further Development}

The expectation of this method in the future is improvement of accuracy from GPS/IMU technology. The accuracy that expected will significantly eliminate parallax in stereomodel generated by EO parameter from Direct Georefrencing method. And it can use for stereocompilation. If it can be realized, AT process can be truly bypassed in digital photogrammetry workflow.

\subsection{Integrated Sensor Orientation}

Another method that emerged due to GPS/IMU technology is Integrated Sensor Orientation (ISO). This method combine both Direct Georeferencing and Aerial Triangulation method. It still need GCP and measurement of tie point for each stereomodel, but the requirement of GCP can be reduced significantly. EO parameter derived from GPS/IMU used in Bundle Adjustment calculation from AT and the calculation obtain a good result at high accuracy with no parallax and ready for stereocompilation using stereomodel.

This method is most suitable when GPS/IMU which used is less accurate. In the other word, when this method will conducted, it is not a compulsory to use a high accurate GPS/IMU which is very expensive. A further research is need to determine the minimum number of GCP, since it is a cost factor for this method.

\section{CONCLUSION}

From this research, it can conclude that Direct Georeferencing method is a new technology which has ability to provide data for high accuracy mapping. It has several advantages, main advantages are faster period, simple workflow and low cost project. Direct Georeferencing is a good option especially for orthoimages generation, single image recification or DEM generation from imagematching. Stereoplotting is possible but it must be examined if there is still y-parallax exist.

\section{REFERENCES}

Amhar, Fahmi., 2000. Report Paper to German Technical Cooperation "Comprehensive Analysis on Accuracy and Quality Data".

Mostafa, M., Hutton, J., Lithopoulos, E., 2001a. The $3^{\text {rd }}$ International Symposium on Mobile Mapping Technology “ Airborne Direct Georeferencing of Frame Imagery: An Error Budget", Cairo, Egypt http://www.simwright.com/techpapers/POS-

AV/POS\%20AV_4_Airborne\%20Direct\%20Georeferencing.pd f (18 Jan 2012)

Mostafa, M., Hutton, J., 2001b. Proceedings, American Society of Photogrammetry and Remote Sensing Annual Meeting "Direct Positioning and Orientation Systems, How Do They Work? What is The Attainable Accuracy?", St. Louis, USA. http://www.simwright.com/techpapers/POS-

AV/POS\%20AV_2_Direct\%20Positioning.pdf (18 Jan 2012)

Mostafa, M., Hutton, J., 2001c. Proceedings, International Symposium On Kinematic Systems in Geodesy, Geomatics, and Navigation "Airborne Kinematic Positioning and Attitude Determination

Without Base Stations", Alberta, Canada. http://www.ucalgary.ca/engo_webdocs/SpecialPublications/KIS \%2001/PDF/0409.PDF (18 Jan 2012)

Madani, M., Mostafa, M., 2001. Proceedings of OEEPE Workshop: Integrated Sensor Orientation "ISAT Direct Exterior Orientation QA/QC Strategy Using POS Data”, Hanover, Germany.

http://www.applanix.com/media/downloads/articles_papers/PO SAV_2001_09_ISATDirectExterior.pdf (18 Jan 2012)

Scroth, Ralf., 2004. International Federation of Survey. Article of the Month, May "Direct Geo-Referencing in Practical Application"

http://www.fig.net/pub/monthly_articles/may_2004/schroth.pdf (16 Jan 2011)

Skaloud, Jan., 2007. Reliability of Direct Georeferencing Beyond the Achilles' Heel of Modern Airborne Mapping. Photogrammetric Week 2007, pp. 227-241

http://www.ifp.uni-

stuttgart.de/publications/phowo07/250Skaloud.pdf $\quad\left(\begin{array}{ll}16 & \text { Jan }\end{array}\right.$ 2011) 